\title{
Spectroscopic and catalytic studies of lipases in ternary hexane-1-propanol-water surfactantless microemulsion systems
}

\author{
Maria Zoumpanioti ${ }^{a}$, Haralambos Stamatis ${ }^{b, * *}$, \\ Vassiliki Papadimitriou ${ }^{\mathrm{a}}$, Aristotelis Xenakis ${ }^{\mathrm{a}, *}$ \\ a Institute of Biological Research and Biotechnology, The National Hellenic Research Foundation, Athens, Greece \\ b Biological Applications \& Technologies Department, University of Ioannina, 45110 Ioannina, Greece
}

Received 27 July 2005; received in revised form 8 November 2005; accepted 11 November 2005

\begin{abstract}
A series of water-in-oil microemulsion systems formulated without surfactant were used to solubilize lipases from Rhizomucor miehei and Candida antarctica B. The effect of the system's composition on the velocity of enzymic reactions was investigated following a model esterification reaction. The interaction between enzymes and the microemulsion environment was studied by steady state fluorescence spectroscopy. The site of localization of the enzyme within the different microdomains of the dispersed phase was investigated by applying the fluorescence energy transfer technique. To determine the properties of the interface of water in organic solvent surfactantless microemulsion systems the Electron Paramagnetic Resonance (EPR) spectroscopic technique was applied. The results indicated that even at low water content, water-rich structures are formed. This was confirmed by conductivity measurements. By the addition of enzyme it was observed that when the aqueous phase of the surfactantless microemulsion systems exceeds $2 \%(\mathrm{v} / \mathrm{v})$ the enzyme retains its catalytic activity, as it is located within the water pools that protect it from the organic solvent. These confined water phases show a propanol rich interface with hexane and their structure depends on the system's composition. (C) 2005 Published by Elsevier B.V.
\end{abstract}

Keywords: Biocatalysis; Microemulsion; Lipase; Spin probe; Energy transfer

\section{Introduction}

Lipases (EC 3.1.1.3) are important industrial enzymes, which catalyze the hydrolysis of fats and oils and can also play a role in the synthesis of various useful esters [1]. However, water is not the ideal medium for reactions catalyzed by lipases, as the activity of these enzymes is greatly increased at the lipid-water interface, a phenomenon known as interfacial activation [2]. One of the models proposed to explain the interfacial activation suggests the conformational change of the lipase, which depends on its environment [3] and is usually triggered in waterin-oil (w/o) microemulsions [4]. Thus, w/o microemulsions [5] have been used as ideal media for lipase catalysis. In these

\footnotetext{
* Corresponding author. Tel.: +30 2107273 762; fax: +30 2107273758 .

** Corresponding author. Tel.: +30 2651097 360; fax: +30 2651097064 .

E-mail addresses: hstamati@cc.uoi.gr (H. Stamatis), arisx@eie.gr (A. Xenakis).
}

systems, the enzyme molecules are entrapped into aqueous cavities of spherical reversed surfactant micelles and thus protected from denaturation [6,7]. However, practical applications by w/o microemulsions may be hindered by the necessity of reusing the catalyst and separating the surfactant from the reaction products. These difficulties may be avoided by using surfactantless microemulsion systems consisting of hydrocarbon, alcohol and water.

These ternary mixtures (also known as surfactantless microemulsions) consisting of a non-polar organic solvent, a short chain-alcohol and water represent thermodynamically stable and optically transparent aqueous dispersions in the hydrocarbon solvent and have been shown to serve as appropriate media for enzymatic catalysis [5-8]. These ternary systems have the ability to dissolve both hydrophobic and hydrophilic reagents, are presumed to possess a significant interfacial area and can be prepared from inexpensive non-toxic solvents. An important advantage of using such systems as a reaction medium 
is that the separation of the reaction products as well as the enzyme reuse may be facilitated as compared to classic reverse micellar systems. In addition, the solubility of relatively polar compounds in such systems is high due to the presence of large amounts of the polar alcohol.

The aim of this work was to study the catalytic behavior of lipases from Rhizomucor (former Mucor) miehei (RmL) and Candida antarctica $\mathrm{B}(\mathrm{CaL})$ in surfactantless microemulsion systems consisting of $n$-hexane, 1-propanol and water, in relation to the microstructure of the dispersed phase. The choice of the specific lipases was based on the interface activation of the enzyme exhibited by the RmL one and not by the CaL. The literature concerning the structure and the microenvironment of such surfactantless microemulsion systems is quite scarce [9]. Thus, our intension was to enrich our knowledge on some structural aspects of such surfactantless microemulsion systems in relation to the localization of lipases and their catalytic activity in these systems. We applied, thus, fluorescence spectroscopy including steady state and energy transfer measurements, conductivity measurements, as well as the EPR spectroscopic technique [10,11].

Enzymes are proteins that contain naturally occurring fluorophores, with tryptophan being the most highly fluorescent amino acid in their molecule, which accounts for about $90 \%$ of the total fluorescence of enzymes [12]. This fluorescence is sensitive to the polarity of the tryptophan surrounding environment. This allows conclusions about the enzyme localization to be drawn by applying steady state fluorescence spectroscopy. Moreover, specific information concerning the topology of the enzyme in relation to the various microphases of the system can be retrieved by applying the fluorescence energy transfer technique [12]. Information about the structure of the interface between the aqueous and the organic phase of such microheterogeneous systems can be monitored by applying EPR spectroscopy [13]. Additional information about the structure of the system in the presence and in the absence of the enzyme can be obtained by conductivity measurements $[14,15]$.

\section{Experimental}

\subsection{Materials}

Lipase from $R$. miehei was supplied by Fluka (as lipase from Mucor miehei). The enzyme preparation used in the various experiments had a specific activity of $2.1 \mathrm{U} \mathrm{mg}^{-1}$ of protein $(1 \mathrm{U}$ corresponds to the amount of enzyme which liberates $1 \mu \mathrm{mol}$ butyric acid per minute at $\mathrm{pH} 7.5$ and $40^{\circ} \mathrm{C}$ using tributyrine as substrate). C. antarctica lipase B was supplied by Fluka. The enzyme preparation used in the various experiments had a specific activity of $9.2 \mathrm{U} \mathrm{mg}^{-1}$ of protein (1 $\mathrm{U}$ corresponds to the amount of enzyme which liberates $1 \mu \mathrm{mol}$ butyric acid per minute at $\mathrm{pH} 8.0$ and $50^{\circ} \mathrm{C}$ using tributyrine as substrate). The enzymes were solubilized in $0.2 \mathrm{M}$ Tris/ $\mathrm{HCl}$ buffer, $\mathrm{pH} 7.5$ and stored frozen. L-Tryptophan was supplied by BHD biochemicals. 99\% cis-parinaric acid [9,11,13,15]-cis,trans,trans, cis-octadeca-tetraenoic acid (PNA)

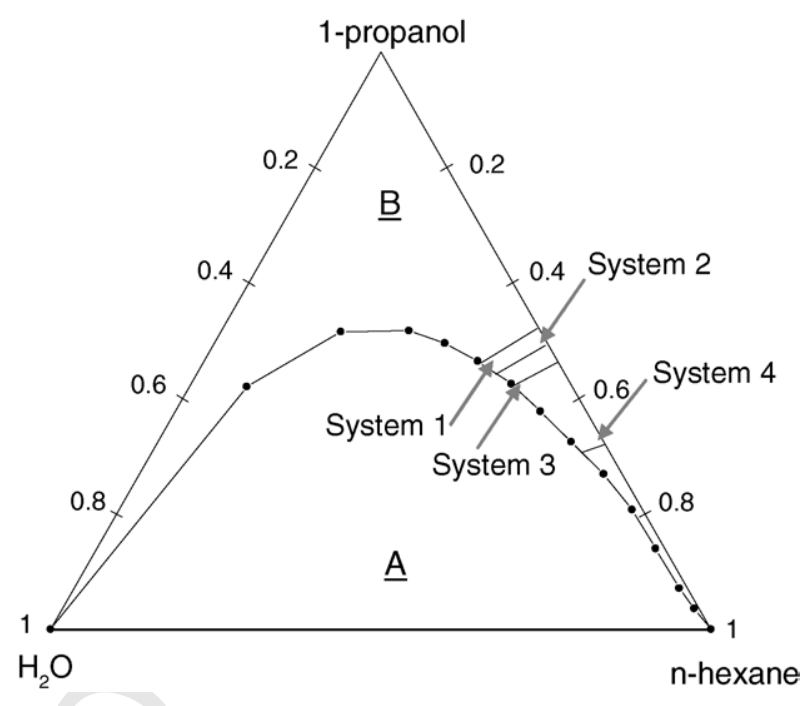

Fig. 1. A triangular phase diagram of the system $n$-hexane/1-propanol/water. Compositions are given in mole fractions. Region B corresponds to monophasic systems. The lines within the region B represent the samples used (Table 1).

was obtained from Molecular Probes, OR. Stock solutions of PNA in surfactantless microemulsions were prepared and stored at $-20{ }^{\circ} \mathrm{C}$ in the presence of $0.1 \mathrm{mg} / \mathrm{ml}$ BHT $(2,6$-ditert-4-methylphenol) as antioxidant [16]. The spin-labeled fatty acid 5-doxyl stearic acid [5-(1-oxyl-2,2-dimethyloxazolidin) stearic acid], 5-DSA, was purchased from Sigma. All other reagents were of the highest commercially available purity.

\subsection{Preparation of the microemulsion systems}

The surfactantless microemulsion systems were prepared by mixing the required volumes of $n$-hexane and 1-propanol. Then, the aqueous phase (Tris/HCl buffer, $\mathrm{pH}$ 7.5) containing the enzyme was added and the final water content of the system was adjusted by addition of the required amount of buffer. In all cases, the final volume was $1 \mathrm{ml}$. The mixture was shaken using a vortex until transparency appears. No further equilibration of the systems was needed. The compositions of the systems examined were chosen to correspond to the monophasic area (area B) of the phase diagram that is presented in Fig. 1. The lines indicated as Systems 1-4 correspond to the systems examined. The exact compositions of these systems are given in Table 1.

Table 1

Composition of the surfactantless microemulsions

\begin{tabular}{lll}
\hline Series & $n$-Hexane/1-propanol (v/v) & Water $(\%, \mathrm{v} / \mathrm{v})$ \\
\hline System 1 & $47.2 / 50.8$ & $1-10$ \\
System 2 & $53.4 / 43.4$ & $1-5$ \\
System 3 & $55.7 / 39.7$ & $1-5$ \\
System 4 & $71.1 / 27.7$ & $1-2$ \\
\hline
\end{tabular}

In each series the volume ratio $n$-hexane to 1-propanol is kept constant while the water content of the prepared microemulsions varied as described in every case. 


\subsection{Lipase-catalyzed reactions}

The determination of lipase activity was based on the measurement of the initial rate of lauric acid ester synthesis. Laurie acid of a fixed concentration of $0.2 \mathrm{M}$ was added to solutions of $n$-hexane and 1-propanol. The composition of the systems examined is given in Table 1 . The reaction was initiated by the addition of the enzyme solution. The reaction took place at $30^{\circ} \mathrm{C}$. At fixed time intervals, samples of $10 \mu l$ each were withdrawn and analyzed by GC. An HP- 5 capillary column $(30 \mathrm{~m} \times 0.32 \mathrm{~mm}$ i.d., $0.25 \mu \mathrm{m}$ film thickness) mounted on a Hewlett-Packard (HP) Model GC-6890 was used for the analysis [17].

\subsection{Steady state fluorescence spectroscopy}

In order to monitor the steady state fluorescence emission spectra, a series of surfactantless microemulsions was prepared using different hexane to 1-propanol volume ratios that correspond to the monophasic area of the phase diagram (Fig. 1). In each case, the aqueous phase of the system was constituted by Tris-HCl buffer $\mathrm{pH} 7.5$ containing the lipase. The measurements were made right after the addition of the enzyme. The excitation wavelength was $280 \mathrm{~nm}$ while the emission wavelength varied between 300 and $400 \mathrm{~nm}$. All experiments were carried out at $25^{\circ} \mathrm{C}$. The fluorescence emission spectra were monitored using a Jobin Yvon-SPEX fluorometer at $25^{\circ} \mathrm{C}$.

\subsection{Fluorescence energy transfer}

Energy transfer was examined by measuring the effect of the concentrations of PNA on lipase fluorescence. To obtain the desirable concentrations of PNA, appropriate amounts of stock solutions: $n$-hexane/1-propanol/PNA and $n$-hexane/1-propanol were previously mixed. This procedure was carried out in a series of microemulsions (Table 1) with different volume fractions of the aqueous phase. The concentration of PNA ranged from $0.9 \times 10^{-5}$ to $3.6 \times 10^{-5} \mathrm{M}$. The concentration of the lipase was kept constant $\left(2 \times 10^{-6} \mathrm{M}\right)$. The effect of the PNA concentration on the energy transfer efficiency has been studied for the lipase as well as for free tryptophan. The energy transfer efficiency (T) between the donor-acceptor pair was determined from the reduction of the donor (tryprophan residues or free tryptophan) fluorescence intensity in the presence of different concentrations of acceptor (PNA), as described by Eq. (1) [18].

$T=1-\frac{F}{F_{0}}$

$F_{0}$ and $F$ refer to the fluorescence intensity of the donor in the absence and presence of acceptor, respectively. The Förster distance can be calculated by Eq. (2).

$$
T=\frac{R_{0}^{6}}{R_{0}^{6}+r^{6}}
$$

where $r$ represents the distance between donor and acceptor and $R_{0}$ the Förster distance [12], calculated from the spectral overlap, $J$, and the quantum yield, $\Phi_{\mathrm{d}}$, determined independently [12]
The excitation wavelength for tryptophan and lipase was $280 \mathrm{~nm}$. Emission was recorded between 300 and $500 \mathrm{~nm}$.

\subsection{EPR spectroscopy}

In order to obtain the desired concentrations of 5-DSA in the $n$-hexane/1-propanol/water surfactantless microemulsion systems tested, $1 \mathrm{ml}$ of each system was added to a tube into which the appropriate amounts of 5-DSA had previously been deposited. This was done by placing $10 \mu \mathrm{l}$ of a $7.8 \times 10^{-3} \mathrm{M}$ ethanol solution in the tube and by further evaporating the ethanol $[19,20]$.

EPR spectra were recorded at room temperature using a Bruker ER 200 D spectrometer operating at X-band. Spectra were accumulated and treated using the DAT-200 software for PC (University of Lubeck). The samples were contained in an E248 cell. Typical settings were: center field, $3460 \mathrm{G}$; scan width, $100 \mathrm{G}$; time constant, $0.5 \mathrm{~s}$; scan time, $100 \mathrm{~ms}$; microwave frequency, $9.76 \mathrm{GHz}$; modulation amplitude, $1 \mathrm{G}$.

The rotational correlation time parameter, $\tau_{\mathrm{R}}$, can be used to monitor the dynamics of a spin probe and is calculated using the following Eq. (3) [21]:

$\tau_{\mathrm{R}}=6 \times 10^{-10}\left[\left(\frac{h_{0}}{h_{+1}}\right)^{1 / 2}+\left(\frac{h_{0}}{h_{-1}}\right)^{1 / 2}-2\right] \Delta H_{0}(s)$

Here $h_{+1}, h_{0}$ and $h_{-1}$ are the intensities of the low, center and high field peaks of the EPR spectrum, respectively, and $\Delta H_{0}$ is the width of the central line. Eq. (3) is applicable in the fast motion region, i.e. for rotational correlation times in the range of $10^{-11}<\tau_{\mathrm{R}}<3 \times 10^{-9} \mathrm{~s}[19]$.

Furthermore, from the EPR spectra the hyperfine coupling constant $\alpha_{\mathrm{N}}$ of the spin probe can be calculated as the distance between the low and center field peaks at the baseline level. This parameter reflects the polarity of the immediate environment of the spin probe.

\subsection{Conductivity measurements}

The conductivity measurements are carried out with a Metrohm 644 conductometer. The samples are prepared as described above and the measurements are possible due to the presence of Tris/ $\mathrm{HCl}$ buffer in the systems. The experiments took place at $28^{\circ} \mathrm{C}$. The cell constant, $c$, was equal to $0.1 \mathrm{~cm}^{-1}$.

\section{Results}

\subsection{Lipase-catalyzed reactions}

In order to study the effect of the aqueous phase volume fraction on the initial rate of enzymic reactions, a series of ternary systems was prepared with the aqueous contents ranging from 0.6 to $4.6 \%$ (Table 1). The enzyme concentration was $2 \times 10^{-5} \mathrm{M}$ for RmL and $10.8 \times 10^{-5} \mathrm{M}$ for CaL. The reaction studied was the esterification of lauric acid with 1-propanol contained as a constituent in all surfactantless microemulsion systems. It should be mentioned here, that the consumption of 
Table 2

Effect of the aqueous phase ratio on the initial rate of Laurie acid propyl ester synthesis catalyzed by $\mathrm{CaL}$ and $\mathrm{RmL}$ lipases in three surfactantless microemulsions (compositions given in Table 1)

\begin{tabular}{|c|c|c|c|c|c|c|}
\hline \multirow[t]{2}{*}{$\begin{array}{l}\text { Aqueous } \\
\text { phase }(\%)\end{array}$} & \multicolumn{3}{|c|}{$\begin{array}{l}\text { Candida antarctica } \\
\text { lipase }\end{array}$} & \multicolumn{3}{|c|}{$\begin{array}{l}\text { Rhizomисоr miehei } \\
\text { lipase }\end{array}$} \\
\hline & System 1 & System 2 & System 3 & System 1 & System 2 & System 3 \\
\hline 0.6 & 80 & 51 & & 43 & 49 & \\
\hline 1.0 & & 20 & 7 & & 37 & 27 \\
\hline 2.0 & 24 & 18 & 20 & 44 & 22 & 22 \\
\hline 3.0 & 40 & & 24 & 42 & & 71 \\
\hline 3.2 & & 21 & & & 83 & \\
\hline 4.0 & 66 & & & 58 & & \\
\hline 4.6 & & & 45 & & & 122 \\
\hline
\end{tabular}

The initial rate was expressed as $\mu \mathrm{M} / \mathrm{min}$.

1-propanol during this process does not affect the stability of the systems. Both enzymes retained their catalytic ability in the systems studied and the effect of the aqueous volume fraction on the reaction's initial rate is presented in Table 2.

The initial rate of the enzymatic esterification examined here not only depends on the enzyme used, but also on the composition of the system. For a given system, in the case of CaL, increasing the water content up to $2 \%$ the initial rate decreases, whereas beyond that value the reaction rate is increased. In the case of RmL, the initial rate has the tendency to remain unaffected by the increase of the water content up to the same point $(2 \%, v / v$, water) and then increases in a similar way. We can also observe that, for a given catalyst, the initial rate of the synthesis is affected by the composition of the system. At low water content, the enzyme's catalytic activity is higher in the system with high propanol content (System 1) and much lower in the system with the less propanol (System 3). Furthermore, when the water content increases above $2 \%(\mathrm{v} / \mathrm{v})$ a general tendency of the initial rate to increase is observed.

\subsection{Steady state fluorescence spectroscopy}

The emission spectra of $\mathrm{CaL}$ and $\mathrm{RmL}$ were recorded in a series of surfactantless microemulsions using different compositions. In the case of RmL, we can observe a fluorescence emission shift to higher wavelengths when the aqueous phase in the system increases, tending to reach the value obtained in an aqueous solution (Fig. 2). However, in the case of CaL the emission maxima do not vary significantly being close to the emission maximum value determined in water (Fig. 2). The horizontal lines correspond to the emission maxima of the two lipases recorded in water: $348 \mathrm{~nm}$ for $\mathrm{RmL}$ and $328 \mathrm{~nm}$ for CaL.

\subsection{Fluorescence energy transfer}

A considerable overlap occurring between the absorption spectrum of PNA and the emission spectrum of lipase was observed (data not shown) suggesting that fluorescence energy transfer between the pair PNA and tryptophan residues of lipase occurs $[9,10]$. The fluorescence energy transfer between PNA and the tryptophan residues of the RmL in the present

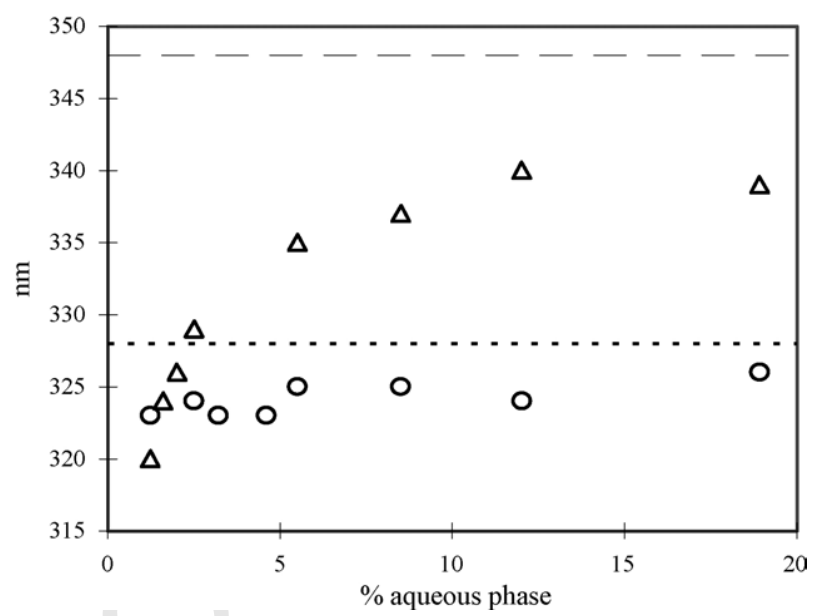

Fig. 2. Effect of the systems aqueous phase volume fraction on the fluorescence emission for $\operatorname{RmL}(\triangle)$ and $\mathrm{CaL}(\bigcirc)$. The horizontal lines indicate the fluorescence emission of (--) RmL and (- - ) CaL in aqueous solution.

microemulsions was examined by measuring the fluorescence of lipase in the absence and in the presence of various PNA concentrations at constant aqueous phase volume fractions.

The results showed that as the concentration of PNA increases the fluorescence of the lipase decreases. This can be attributed to Förster type energy transfer as already shown for systems in homogeneous media [22]. As can be seen in Fig. 3, for certain PNA concentrations, the energy transfer efficiency decreases upon increase of the water content of the system. This leads to the conclusion that the distance between the donor and the acceptor pair becomes longer.

Table 3 shows the values of the determined parameters used for the calculation of the Förster distance, $R_{0}$, as well as the calculated donor-acceptor distance, $r$ (Eq. (2)). As it can be seen, the distance $r$ within each series of systems examined appears to increase slightly upon water content increase, with this increment being $1 \AA$ for System 1, $2 \AA$ for System 2, $3 \AA$ for System 3 and $3 \AA$ for System 4 .

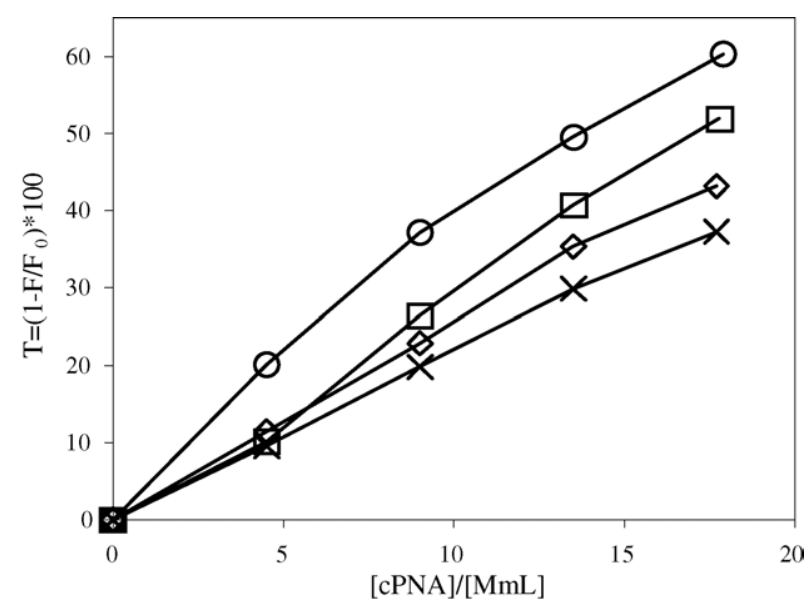

Fig. 3. Fluorescence energy transfer efficiency $(T)$ for $\mathrm{RmL}$ in the presence of various PNA concentrations in System 4: 71.1/27.7 (v/v) $n$-hexane/1-propanol. Water content in the system: $0.6 \%(\bigcirc) ; 0.9 \%(\square) ; 1.2 \%(\diamond) ; 1.5 \%(\times)$. [Lipase] $=2 \times 10^{-6} \mathrm{M} ; \lambda_{\mathrm{ex}}=280 \mathrm{~nm} ; \lambda_{\mathrm{em}}=300-500 \mathrm{~nm}$. 
Table 3

Calculation of the donor-acceptor distance, $r$, from the energy transfer efficiency, $T$, measured for $\mathrm{RmL}$ in three surfactantless microemulsions

\begin{tabular}{lllllll}
\hline System & $\begin{array}{l}\text { Aqueous } \\
\text { phase (\%) }\end{array}$ & $\Phi_{\mathrm{d}}{ }^{\mathrm{a}}$ & $J^{\mathrm{a}}\left(\mathrm{M}^{-1} \mathrm{~cm}^{3}\right)$ & $R_{0}(\AA)$ & $T$ & $r(\AA)$ \\
\hline 1 & 0.6 & 0.011 & $1.1 \times 10^{-13}$ & 23 & 0.616 & 21 \\
1 & 4.0 & 0.018 & $1.2 \times 10^{-13}$ & 25 & 0.681 & 22 \\
2 & 0.6 & 0.012 & $1.7 \times 10^{-13}$ & 25 & 0.586 & 24 \\
2 & 3.2 & 0.015 & $2.0 \times 10^{-13}$ & 26 & 0.496 & 26 \\
3 & 1.0 & 0.007 & $1.0 \times 10^{-13}$ & 21 & 0.468 & 21 \\
3 & 4.6 & 0.015 & $1.3 \times 10^{-13}$ & 24 & 0.499 & 24 \\
4 & 0.6 & 0.020 & $1.6 \times 10^{-13}$ & 26 & 0.447 & 27 \\
4 & 1.5 & 0.029 & $1.9 \times 10^{-13}$ & 29 & 0.453 & 30
\end{tabular}

Compositions as described in Table 1.

${ }^{a} J$ is the spectral overlap; $\Phi_{\mathrm{d}}$ is the quantum yield [12].

\subsection{EPR spectroscopy}

To determine the properties of the interface between the aqueous phase and the organic solvent within the surfactantless microemulsion systems we have applied the EPR spectroscopic technique by using the spin probe 5-DSA. This interface-located fatty acid probe gives EPR spectra reflecting the mobility of the probe and the polarity of its environment [13]. Fig. 4 shows the obtained EPR spectra of 5-DSA recorded in $n$-hexane-1propanol-water ternary System 1 at various water concentrations. As can be observed, when the water content of the system

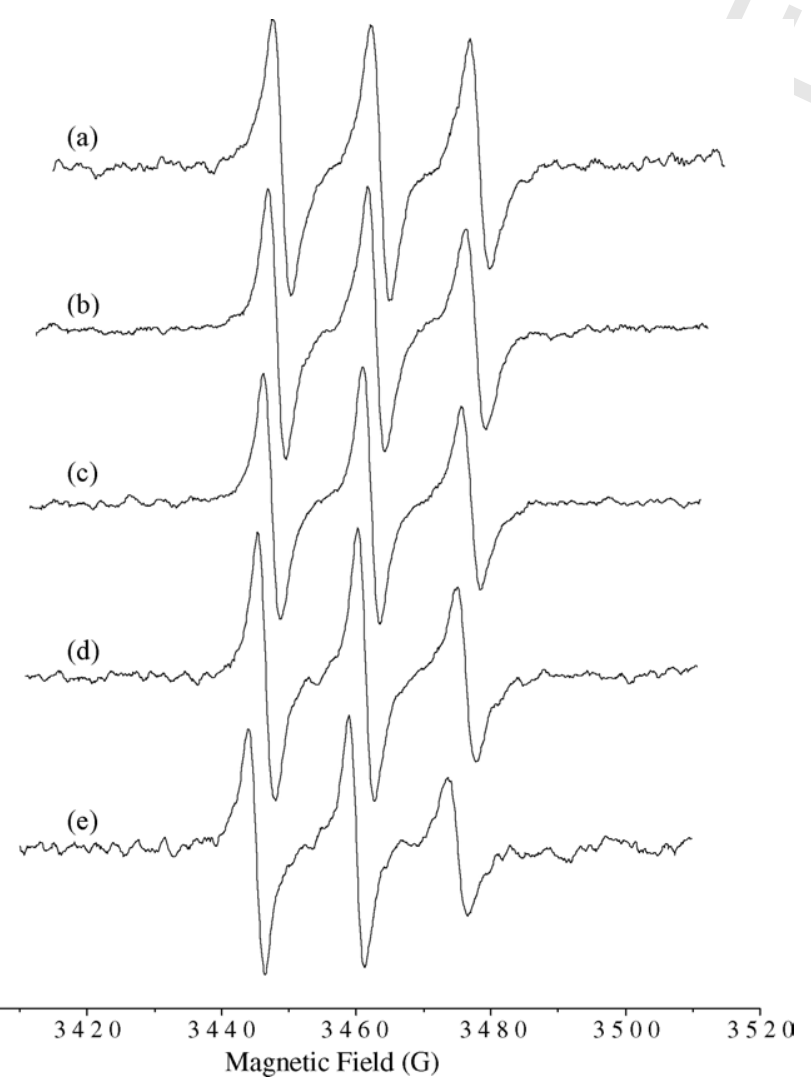

Fig. 4. EPR spectra of 5-DSA in ternary System 1: $n$-hexane 47.2/1-propanol $50.8(\mathrm{v} / \mathrm{v})$, at various water concentrations. Water content (v/v): $0 \%(\mathrm{a}) ; 1 \%(\mathrm{~b})$; $4 \%$ (c); $7 \%$ (d); $10 \%$ (e). [5-DSA] $=7.8 \times 10^{-5} \mathrm{M}$.

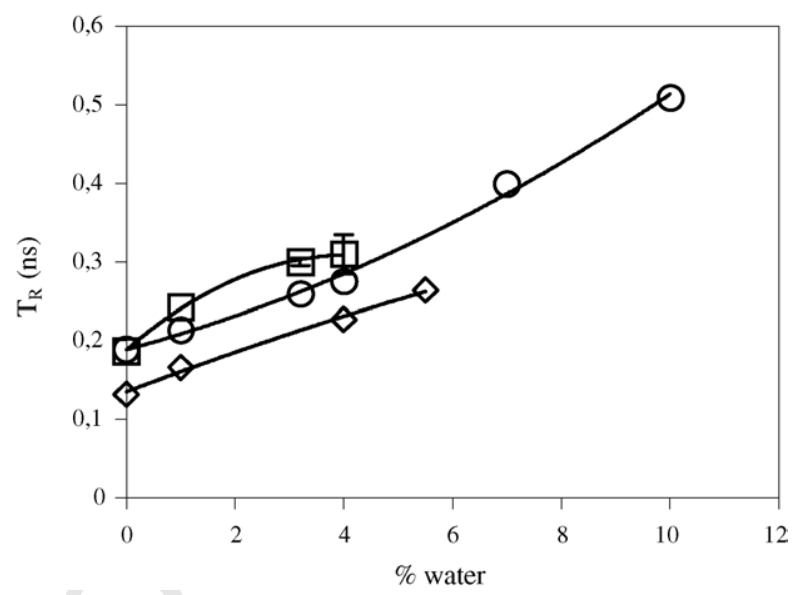

Fig. 5. Variation of the rotational correlation time, $\tau_{\mathrm{R}}$, of the 5-DSA as a function of water content in the $n$-hexane-1-propanol-water surfactantless microemulsion systems, ( $\bigcirc)$ System 1; $(\square)$ System 2; $(\diamond)$ System 3 (compositions given in Table 1). $[5-\mathrm{DSA}]=7.8 \times 10^{-5} \mathrm{M}$. An estimation of the error is given by the corresponding error-bars.

increases, the spectrum slightly changes as the peaks become shorter and wider. The above observation is confirmed by the values of the spectral characteristics, namely $h_{-1}, h_{0}, h_{+1}$ and $\Delta H_{0}$ of Eq. (3).

Fig. 5 shows the effect of the water content of the Systems 1-3 (compositions shown in Table 1) on the rotational time values, $\tau_{\mathrm{R}}$, of 5-DSA calculated from Eq. (3). We can see that as long as the water content increases, an increase of the $\tau_{R}$ can be observed in all the systems examined.

\subsection{Conductivity}

The conductivities of the four systems examined were measured in the presence and absence of enzyme. Fig. 6 shows the variation of the conductivity as a function of the water content of the System 1 at $28^{\circ} \mathrm{C}$. It can be seen that conductivity increases upon water content increase and the addition of enzyme does not affect this pattern.

In Fig. 7 is presented the conductivity of the four systems examined as a function of the water content. As can be seen,

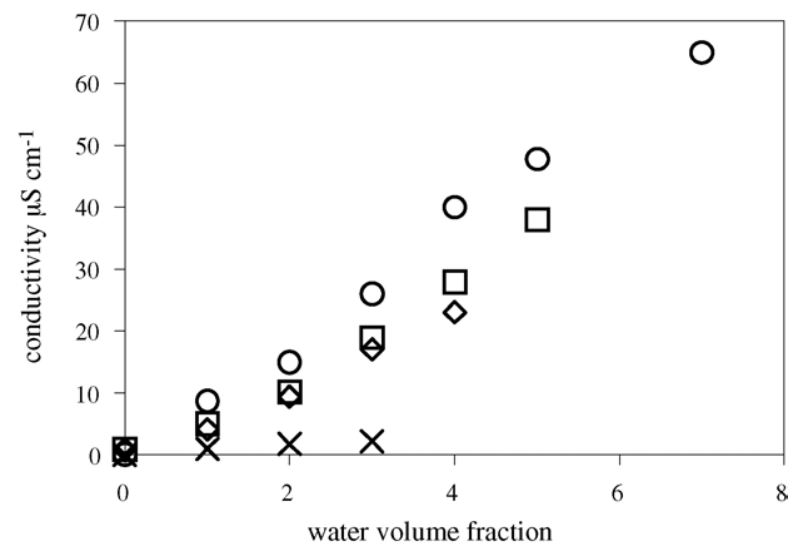

Fig. 6. Variation of the conductivity of System 1 as a function of water content in the absence $(\square)$ and in the presence $(\bigcirc)$ of $\mathrm{RmL}$. 


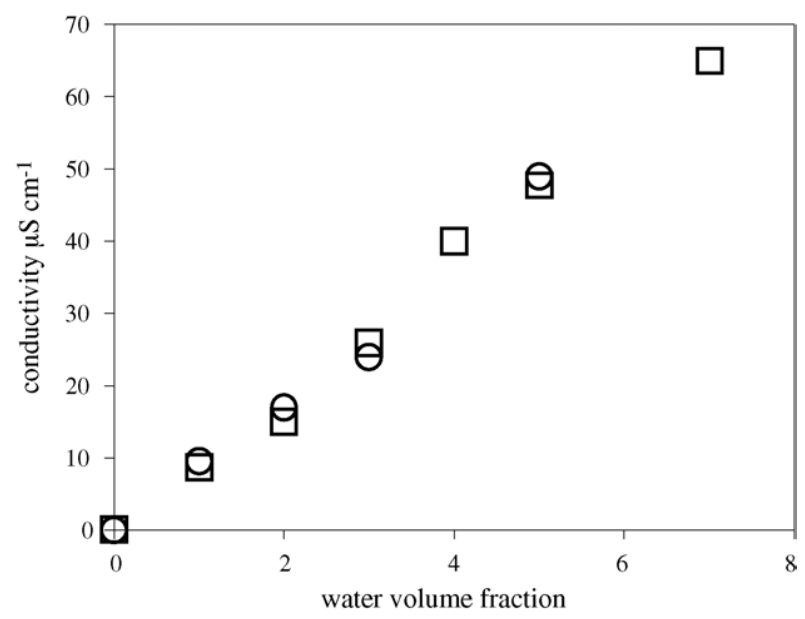

Fig. 7. Variation of the conductivity of System $1(\bigcirc)$; System $2(\square)$; System 3 $(\diamond)$; System $4(\times)$ as a function of water content.

the conductivity increases upon water content increase and the higher content of 1-propanol leads to higher conductivity values.

\section{Discussion}

All lipases show a common $\alpha-\beta$ hydrolase fold [23] and a catalytic triad, which constitutes the active site. In most cases, the active site is covered by a helical surface loop or 'lid' that makes it inaccessible to substrates. A typical example is the molecule of $\mathrm{RmL}$, where the lid is consisted by residues $82-96$ [24]. This structural characteristic is related to the interfacial activation phenomenon shown by RmL. On the other hand, $\mathrm{CaL}$ lacks interfacial activation probably because of the absence of a well defined lid, although, a small helix has been suggested to act as one [25]. The catalytic activity of the lipases is strongly related to the conformation of the enzyme that allows access to the active site.

Lipids [26,27], surfactants [28,29] and organic solvents [30] induce a movement of the helical lid, which reveals the active site. It has also been proved that propanol not only induces the open conformation of the enzyme [31], but also stabilizes the molecule in this position [29,30]. Therefore, we can assume that the retained catalytic activity of the two lipases studied here can be attributed to the presence of propanol in the surfactantless microemulsion systems.

As can be seen in Table 2, the catalytic activity of both enzymes increases only when the water content of the systems exceeds $2 \%(\mathrm{v} / \mathrm{v})$. A possible explanation for this behavior can be attributed to the microenvironment of the enzyme. It seems that in low water concentrations the enzyme does not have an aqueous barrier surrounding it and it gets denaturated and thus the reaction rate is slow. By increasing the water content of the system, a protective water microenvironment is formed around the enzyme. From that point and on, water content increase leads to an increase in the reaction rate as well.

It can also be seen in Table 2 that at low water content the catalytic activity of both enzymes is higher when the propanol content increases. A possible explanation may be that when the water and propanol content are low, the enzyme aggregates in an effort to be protected from hexane [29]. When the propanol content increases, the aggregation is reversed as the propanol molecules can protect the hydrophilic parts of the enzyme surface from getting in contact with the apolar hexane molecules. The enzyme forms monomers and thus it presents higher catalytic activity. The same mechanism has been also suggested for Pseudomonas species lipase in zwitterionic detergent micelles and isopropanol-water mixtures [29].

Another explanation could be that when the system's composition is altered, dispersed aqueous aggregates or microdroplets may occur which affects the enzyme's behavior [32]. In order to clarify if there is a protective water microenvironment around the enzyme we investigated whether structural changes in the surfactantless microemulsion systems occur upon variation of the components' quantities. This investigation was carried out by applying steady state fluorescence spectroscopy, fluorescence energy transfer and EPR techniques.

Protein tryptophan residues, which are sensitive to the polarity of their environment, serve as fluorescent spectral probes. It has been determined (RCSB Protein Data Bank, code 3TGL [33]) that $\mathrm{RmL}$ contains four tryptophan residues which are relatively close to the surface [34]. Namely, $14.2 \%$ of Trp38, $10.6 \%$ of Trp223 and 9.7\% of Trp55 [35] are on the surface of the enzyme. Moreover, the residue Trp88 constitutes the central part of the lid [36]. When the enzyme is in the 'closed' conformation $15.1 \%$ of this residue is on the surface [35] and when the enzyme is in the 'open' conformation (as indicated by the catalytic results for the systems studied here) the movement of the helical lid leaves this residue completely exposed [37]. Fig. 8a shows the space-filling model of RmL where three of the tryptophan residues (Trp38, Trp55 and Trp88) are revealed. From another projection after rotation around the $y$-axis by $180^{\circ}$ it is possible to visualize the fourth tryptophan (residue 223) that is partly exposed as well.

On the other hand, CaL (RCSB Protein Data Bank, code 1TCA [25]) contains five tryptophan residues but only two of them are relatively near the surface, while three are almost completely buried in the interior of the protein [34]. Namely, on the surface is $18.1 \%$ of $\operatorname{Trp} 155,12.4 \%$ of Trp65 and only $1.7 \%$ of Trp104, $0.4 \%$ of $\operatorname{Trp} 52$ and $0.0 \%$ of Trp113 [35]. Fig. 8b shows the space filling model of $\mathrm{CaL}$ where three of the tryptophan residues (Trp65, Trp104 and Trp155) are partially visualized, at least to a minimal extend. The other two tryptophans (residues 52 and 113) cannot be visualized by any projection.

The fact that three of the tryptophan residues of $\mathrm{CaL}$ are almost completely buried confirms the observation that this enzyme is not sensitive to the microenvironmental changes due to the increase of the water content of the systems, as regards the low emission maximum observed in water. Moreover, the facts that the spectra of this lipase are not red shifted, and that it retains its catalytic activity, lead to the conclusion that the protein does not unfold in the systems examined. The protein structure apparently is still in its native form that prevents the fluorophores from being exposed to the environment. Thus, a protective aqueous barrier is formed around the enzyme.

The behavior of RmL with its tryptophans exposed to the environment is different. The emission maximum obtained in 

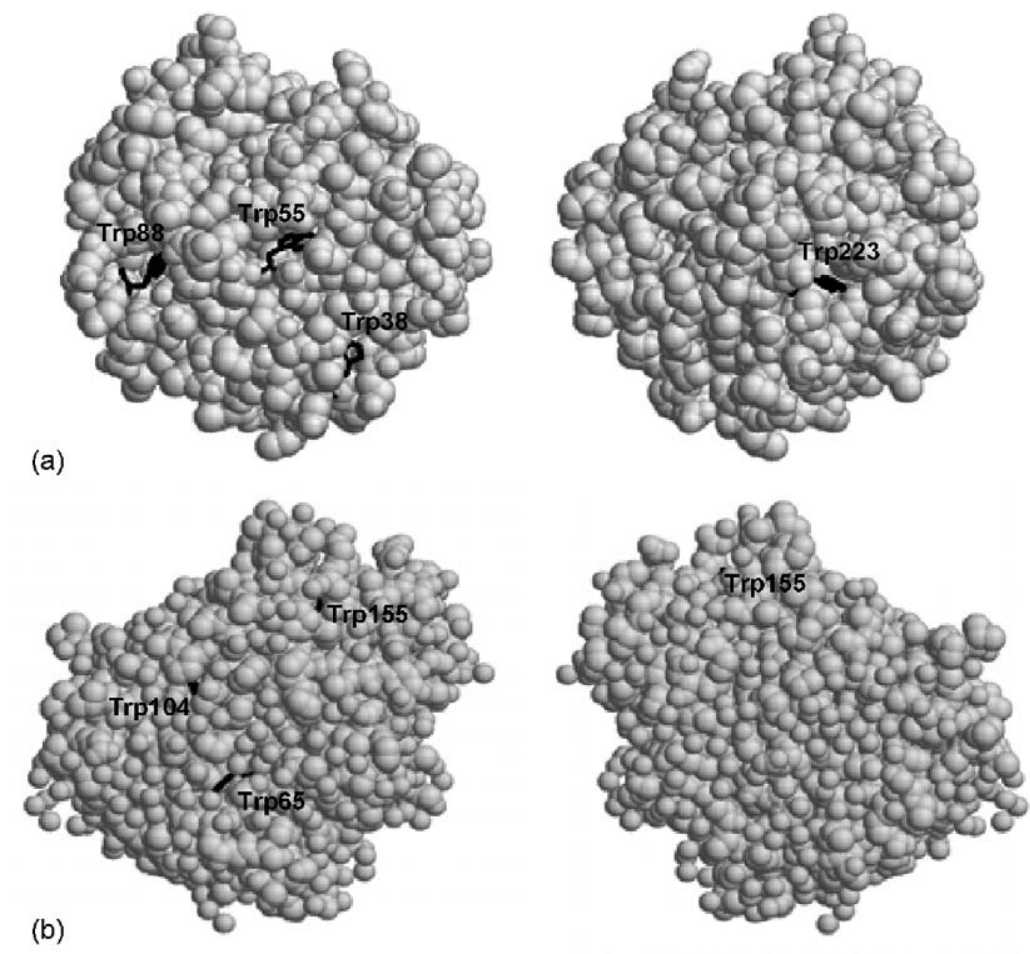

Fig. 8. Three-dimensional crystal structure of RmL [33] and CaL [25] as produced by the RasMol [38] computer program (based on information retrieved from RCSB Protein Data Bank [34]). (a) Space-filling model with the RmL tryptophan residues (black sticks) where three of the tryptophans (residues 38, 55 and 88) can be seen near the surface (left). By rotation around $y$-axis by $180^{\circ}$ the fourth tryptophan (Trp223) can be seen at the surface as well (right), (b) space-filling model with the CaL tryptophan residues (black sticks) where three tryptophans (residues 65, 104 and 155) are shown at least to a minimum extend (left). Even with a rotation around $y$-axis by $180^{\circ}$ the other two tryptophans (Trp52 and Trp113) cannot be visualized (right).

water is quite high, $348 \mathrm{~nm}$, whereas the corresponding values obtained in the ternary systems vary from 320 up to $340 \mathrm{~nm}$, showing a tendency to red shift as the water content of the system increases. This indicates a higher polarity of the fluorophores microenvironment, which leads to the suggestion of an increase of the water barrier around the enzyme. In order to investigate this eventual water barrier in the fluorophore's microenvironment, the fluorescence energy transfer technique has been applied.

Fluorescence energy transfer is primarily a result of dipole-dipole interactions between a donor-acceptor pair and depends on the distance between these two molecules when located in confined media [12]. The fluorescence emission of proteins is due to the aromatic amino acids in their molecule; tyrosine, tryptophan and phenylalanine. By excitation of the proteins in $280-295 \mathrm{~nm}$, the fluorescence is mainly due to the tryptophan residues even at high tyrosine/tryptophan ratios [12]. Consequentially, the main role of the donor molecule is played by the tryptophan residues [22]. Besides, if the fluorescence of the tyrosine could be depicted in the spectra, the quenching of the tryptophan emission would have reveal the tyrosine emission too. Thus, a blue shift of the spectra would have been observed. Our experiments did not reveal a blue shift; we can therefore conclude that the fluorescence emission of the lipase under the experimental conditions is due to the tryptophan residues in its molecule.

The steady state fluorescence measurements led to the conclusion that $\mathrm{RmL}$ is a better probe for fluorescence studies as its tryptophans are exposed and thus the energy transfer fluorescence study that followed was applied with this lipase.

As can be seen in Table 3 for RmL, the distance $r$ within each series of systems examined appears to increase slightly upon water content increase. This indicates the appearance of water microstructures in the continuous organic solvent phase. However, the distance increase is not as high as it would be expected for water in oil microemulsion systems in which spherical reversed micelles exist. Namely, in classic reverse micellar systems the addition of water leads to swelling of the reverse micellar cores, and thus to higher distances $(r)$ [39].

In order to further investigate the properties of the interface around the aqueous phase of these surfactantless microemulsion systems in the absence of enzyme, an EPR spin probing technique has been applied, using the 5-DSA fatty acid. This well-known spin probe is an amphiphile because of its polar head $(-\mathrm{COOH})$ and its hydrophobic $\left(\mathrm{C}_{18}\right)$ moiety. When it is solubilized in systems with components of different polarity, it is localized at the interface intercalating within the membrane molecules [13]. Therefore, the obtained EPR spectra can give information about the mobility of the probe and the polarity of its microenvironment [40,41].

By comparing the spectral shape obtained in the surfactantless microemulsion System 1 for several water contents (Fig. 4), we can observe spectral modifications indicating that the probe's mobility is decreased as water content increases. A similar behavior has been also observed in the other series of surfactantless systems examined (data not shown). 
In order to confirm the above observation, the rotational correlation time $\left(\tau_{R}\right)$ has been calculated from Eq. (3) for the Systems series 1-3 (compositions given in Table 1). At higher water contents, an increase of the $\left(\tau_{\mathrm{R}}\right)$ values of 5-DSA can be observed (Fig. 5) indicating that the mobility of the spin probe is decreased. The fact that even with small changes in water content of the system the mobility of the spin probe is affected, suggests that the probe is located on the interface of two different media, having its polar head in water and the hydrophobic tale in the organic solvent. This implies that water cavities are formed even in the absence of enzyme. By increasing the water content of the surfactantless systems more swelled water-rich structures are formed. The interface of these structures is less curved and as a consequence the mobility of the probe's nitroxide ring is hindered.

As determined from the spectra the values of the hyperfine coupling constant, $\alpha_{\mathrm{N}}$, are not varied upon propanol content at constant water amount. Namely, for $1 \%(\mathrm{v} / \mathrm{v})$ aqueous phase in all systems examined $\alpha_{\mathrm{N}}$ was $14.67 \mathrm{G}$; for $3 \%$ aqueous phase $\alpha_{\mathrm{N}}$ was $14.87 \mathrm{G}$; for $5 \%$ aqueous phase $\alpha_{\mathrm{N}}$ was $15.07 \mathrm{G}$, independently on the propanol content. This indicates that 1-propanol is not localized within the water-dispersed phase. It is preferably located on the interface or solubilized in the organic solvent.

Furthermore, conductivity measurements were carried out, in order to clarify whether the water-rich structures in the systems examined are in contact and to certify that these structures are not affected by the presence of the enzyme. The enzyme molecules are known to form a distinct water layer around their hydrophilic parts in order to be protected. The fact that the conductivity pattern is not altered by the addition of the enzyme (Fig. 6) indicates that the formation of water-rich structures happens upon water addition in the $n$-hexane-1-propanol mixture, independently of the enzyme presence.

According to Fig. 7, even small quantities of water allow ions to move, which means that the water structures communicate. It can also be observed that the systems with higher 1-propanol content exhibit higher conductivity values. This is probably duo to the fact that the alcohol molecules are preferably located at the interface, affecting its fluidity [42]. The location of the alcohol at the interface has already been proposed by the EPR experiments.

\section{Conclusions}

From all the above spectroscopic studies, we can assume that the structure of the surfactantless microemulsion systems depends on the system's composition, which also affects the enzyme behavior. At low water contents the enzyme is not efficiently protected from the organic solvent as indicated by its low catalytic activity. However, when the water content is higher than $2 \%(\mathrm{v} / \mathrm{v})$ the enzyme retains its catalytic activity as it is protected within water pools that get swollen by water content increase. The localization of the enzyme in an aqueous microenvironment is confirmed by the fluorescence emission experiments, whereas the existence of water pools with an interface rich in propanol is indicated by the increase of the donor-acceptor distance as depicted by the fluorescence energy transfer spectroscopy, by the increase of the rotational correlation time of the EPR spin probe
5-DSA and by conductivity measurements. It is obvious thus, that the surfactantless system examined is indeed a water-in-oil microemulsion characterized by the presence of a distinct water dispersed phase with an interface rich in propanol. Furthermore, it is concluded that surfactantless microemulsion systems can be used as reaction media for enzymatic biotransformations. These systems have the advantage of the absence of the often-harmful surfactants facilitating the product recovery.

\section{Acknowledgment}

Dr. E. Chrysina, Institute of Organic and Pharmaceutical Chemistry, The National Hellenic Research Foundation, is acknowledged for her assistance on the protein structure analysis.

\section{References}

[1] E.N. Vulfson, in: P. Wooley, S.B. Petersen (Eds.), Lipases-their Structure, Biochemistry and Application, Cambridge University Press, Cambridge, 1994, p. 271.

[2] L. Sarda, P. Desnuelle, Biochim. Biophys. Acta 30 (1958) 513.

[3] M.R. Aires-Barros, J.M.S. Cabral, in: P. Wooley, S.B. Petersen (Eds.), Lipases-their Structure, Biochemistry and Application, Cambridge University Press, Cambridge, 1994, p. 136.

[4] A. Jutila, K. Zhu, S.A. Patkar, J. Vind, A. Svendsen, P.K.J. Kinnunen, Biophys. J. 78 (2000) 1634.

[5] Y.L. Khmelmtsky, R. Hilhorst, C. Veeger, Eur. J. Biochem. 176 (1988) 265.

[6] C.J. O Connor, D.R. Cleverly, Biocatal. Biotransform. 12 (1995) 193.

[7] E. Topakas, H. Stamatis, P. Biely, D. Kekos, B.J. Macris, P. Christakopoulos, J. Biotechnol. 102 (2003) 33.

[8] Y.L. Khmelnitsky, A.K. Gladilin, I.N. Neverova, A.V. Levashov, K. Martinek, Collect. Czech. Chem. C 55 (1990) 555.

[9] Y.L. Khmelnitsky, A. vanHoek, C. Veeger, A.J.W.G. Visser, J. Phys. Chem. 93 (1989) 872.

[10] H. Stamatis, A. Xenakis, F.N. Kolisis, A. Mallians, Prog. Colloid Polym. Sci. 97 (1994) 253.

[11] S. Avramiotis, H. Stamatis, F.N. Kolisis, A. Xenakis, Prog. Colloid Polym. Sci. 105 (1997) 180

[12] J.R. Lakowicz, Principles of Fluorescence Spectroscopy, Plenum Press, New York, 1983.

[13] C. Taupin, M. Dvolaitzky, in: R. Zana (Ed.), Surfactant Solutions. New Methods of Investigation, Marcel Dekker, New York, 1987, p. 359.

[14] V. Papadimitriou, A. Xenakis, P. Lianos, Langmuir 9 (1993) 912.

[15] F. Pitré, C. Régnaut, M.P. Pilem, Langmuir 9 (1993) 2855.

[16] L.A. Sklar, B.S. Hudson, M. Petersen, J. Diamond, Biochemistry 16 (1977) 813

[17] C. Delimitsou, M. Zoumpanioti, A. Xenakis, H. Stamatis, Biocatal. Biotransform. 20 (2002) 319.

[18] L. Stryer, Ann. Rev. Biochem. 47 (1978) 819.

[19] S. Avramiotis, C.T. Cazianis, A. Xenakis, Langmuir 15 (1999) 2375.

[20] S. Avramiotis, C.T. Cazianis, A. Xenakis, Prog. Colloid Polym. Sci. 115 (2000) 196

[21] N.S. Kommaredi, K.C. O’Connor, V.T. John, Biotechnol. Bioeng. 43 (1994) 215

[22] L.A. Sklar, B.S. Hudson, R.D. Simoni, Biochemistry 16 (1977) 5100.

[23] D.L. Ollis, E. Cheah, M. Cygler, B. Dijkstra, F. Frolow, S.M. Franken, M. Harel, S.J. Remington, I. Silman, J. Schrag, J.L. Sussman, K.H.G. Verschueren, A. Goldman, Protein Eng. 5 (1992) 197.

[24] S. Jääskeläinen, C.S. Verma, R.E. Hubbard, L.S.D. Caves, Theor. Chem. Acc. 101 (1999) 175. 
[25] J. Uppenberg, M.T. Hansen, S. Patkar, T.A. Jones, Structure 2 (1994) 293.

[26] O.G. Berg, Y. Cajal, G.L. Butterfoss, R.L. Grey, M.A. Alsina, B.Z. Yu, M.K. Jain, Biochemistry 37 (1998) 6615.

[27] Y. Cajal, A. Svendsen, V. Girona, S.A. Patcar, M.A. Alsina, Biochemistry 39 (2000) 413.

[28] M. Martinelle, M. Holmquist, K. Hult, Biochim. Biophys. Acta 1258 (1995) 272.

[29] M. Graupner, L. Haalck, F. Spener, H. Lindner, O. Glatter, F. Paltauf, A. Hermetter, Biophys. J. 77 (1999) 493.

[30] K. Zhu, J. Arimatti, T.K.J. Esa, P.K.J. Kinnunen, Protein Sci. 10 (2001) 339.

[31] S. Chamorro, J.M. Sánchez-Montero, A.R. Alcántara, J.V. Sinisterra, Biotechnol. Lett. 20 (1998) 499.

[32] M. Zoumpanioti, M. Karali, A. Xenakis, H. Stamatis, Enzyme Microb. Technol., in press.

[33] A.M. Brzozowski, Z.S. Derewenda, E.J. Dodson, G.G. Dodson, J.P. Tutkenburg, Acta Crystallogr. B 48 (1992) 307.

[34] Retrieved from the RCSB Protein Data Bank, www.rcsb.org/pdb/.
[35] S.J. Hubbard, J.M. Thornton, 'NACCESS', Computer Program, Department of Biochemistry and Molecular Biology, University College London, 1993.

[36] L. Brady, A.M. Brzozowski, Z.S. Derewenda, E. Dodson, G. Dodson, S. Tolley, J.P. Turkenburg, L. Christiansen, B. Huge-Jensen, L. Norskov, L. Thim, U. Menge, Nature 343 (1990) 767.

[37] A.M. Brzozowski, U. Derewenda, Z.S. Derewenda, G.G. Dodson, D.M. Lawson, J.P. Turkenburg, F. Bjorkling, B. Huge-Jensen, S.A. Patkar, L. Thim, Nature 351 (1991) 491.

[38] R. Sayle, E.J. Milner-White, 'RasMol: Biomolecular graphics for all', Trends Biochem. Sci. (TIBS) 20 (1995) 374.

[39] P.L. Luisi, M. Giomini, M.P. Pileni, B.H. Robinson, Biochim. Biophys. Acta 947 (1988) 209.

[40] C.T. Cazianis, A. Xenakis, Prog. Colloid Polym. Sci. 79 (1989) 214.

[41] J.M. Di Meglio, M. Dvolaitzky, C.J. Taupin, Phys. Chem. 89 (1985) 871.

[42] V. Papadimitriou, C. Petit, G. Cassin, A. Xenakis, M.P. Pileni, Adv. Colloid Interface Sci. 54 (1995) 1. 